\title{
Impact of Cytochromes P450 3A4 and 2B6 gene polymorphisms on predisposition and prognosis of acute myeloid leukemia: an Egyptian case-control study
}

\author{
Shahira Kamal Anis Botros ${ }^{1 *} \mathbb{D}$, Nesrine El Gharbawi ${ }^{1}$, Gehan Shahin ${ }^{1}$, Hend Al Lithy ${ }^{2}$ and Mahmoud El Sherbiny ${ }^{3}$
}

\begin{abstract}
Background: It has been postulated that the interaction between environmental risk factors and genetic susceptibility is a possible cause for the development of acute myeloid leukemia (AML). Cytochrome P450 (CYP) detoxification enzymes are responsible for the elimination of oxidative stress. Genetic polymorphisms in these enzymes may cause AML due to enhanced accumulation of reactive oxygen species. To study the association between CYP3A4 (A290G) and CYP2B6 (G516T) gene polymorphisms and the predisposition and prognosis of AML, 50 upfront AML patients and 50 healthy individuals were genotyped for CYP2B6 (G516T) and CYP3A4 (A290G) single-nucleotide polymorphisms (SNPs) using polymerase chain reaction (PCR)-based restriction fragment length polymorphism (RFLP) technique. The polymorphisms were evaluated in relation to the response to chemotherapy and survival.

Results: CYP2B6 gene mutation carries a threefold risk of developing AML (odds ratio [OR], 3.0; 95\% confidence interval [CI], 1.3-6.9), whereas CYP3A4 gene mutation carries approximately fourfold risk (OR, 3.8; 95\% Cl, 1.4-10.1). The presence of combined gene mutation conferred about 15-fold increased risk of developing AML compared with the presence of a single gene mutation $(\mathrm{OR}, 14.8 ; 95 \% \mathrm{Cl}, 1.8-124.2)$. CYP3A4 gene mutation is associated with worse overall survival $(P=0.030)$.
\end{abstract}

Conclusion: CYP enzyme gene polymorphisms are associated with the development of AML. Elimination of oxidative stress in genetically susceptible individuals may decrease the risk of AML and may improve survival.

Keywords: AML, CYP, Gene polymorphism

\section{Background}

Acute myeloid leukemia (AML), which is characterized by the infiltration of the bone marrow (BM), blood, and other tissues by proliferative, clonal, abnormally differentiated and sometimes poorly differentiated cells of hematopoietic origin, is the most common type of acute leukemia in adults $[1,2]$. The etiology of this disease is almost unknown; however, the interaction between

\footnotetext{
* Correspondence: shahirabotros75@outlook.com

${ }^{1}$ Clinical Pathology, Kasr Al Ainy Medical School, 26 Atbara st., Agouza, Giza 12411, Egypt

Full list of author information is available at the end of the article
}

environmental risk factors and genetic susceptibility has been postulated to be a possible cause for the development of AML [3]. Cytochrome P450 (CYP) detoxification enzymes play a crucial role in protecting cells against oxidative damage; CYP metabolizes many exogenous and endogenous genotoxic compounds through the insertion of an atom from molecular oxygen to the substrate, such as hydrogen peroxide [4].

CYP3A4 is the most abundantly expressed CYP in adult human liver; it constitutes approximately 15\%$30 \%$ of the microsomal $\mathrm{P} 450$ pool and is responsible for the metabolism of about $30 \%-40 \%$ of all clinically used 
drugs $[5,6]$. CYP2B6 is also a member of the CYP superfamily $B$ that is mainly expressed in the liver [7].

Certain single-nucleotide polymorphisms (SNPs) at the CYP genetic loci (CYP2D6, CYP1A1, CYP3A5, and $C Y P 2 E 1)$ may be considered as risk factors for many types of cancer and hematological malignancies, such as AML, acute lymphoblastic leukemia, and myelodysplastic syndromes, through the inactivation of enzymatic activity [8-14].

G516T SNP at the CYP2B6 gene locus has been identified as a nonsense polymorphism that reduces the activity of functional protein. Thus, individuals carrying the $\mathrm{T}$ allele (TT) have a lower enzymatic activity than individuals carrying the wild-type G allele (GG), whereas individuals carrying the genotype GT show intermediate activity [15].

CYP3A enzyme activity varies among ethnicities because of interindividual variability; CYP3A4 activity may vary by up to 50 -fold. Most genetic polymorphisms to the CYP3A4 gene result in the decreased function of the enzyme activity. SNPs in the CYP3A4 promoter region (A290G) (i.e., CYP3A4*1B) have been implicated as a possible cause of this variability; subsequently, it may be considered as a risk factor for cancer, but the effects of this SNP remain not well defined [16-19].

This study aimed to evaluate the association between CYP2B6 (G515T) and CYP3A4 (A290G) SNP and AML susceptibility in Egyptian patients and their effect on the response to chemotherapy.

\section{Methods}

\section{Clinical demography}

This study included 50 newly diagnosed AML patients and 50 age- and sex-matched healthy individuals. The study was conducted in accordance with the Declaration of Helsinki and was approved by the Research Ethics Committee of our institute (reference number, I251014). Informed consent was obtained from each participant.

Diagnosis was established between June 2015 and $\mathrm{Au}$ gust 2017, based on the World Health Organization requirements [20] of $20 \%$ of $\mathrm{BM}$ or peripheral blood blasts, except for cases carrying the recurrent cytogenetic abnormalities $\mathrm{t}(15 ; 17), \mathrm{t}(8 ; 21)$, inv.(16), or $\mathrm{t}(16 ; 16)$. Cases were subjected to full history-taking, thorough clinical examination, routine laboratory investigations including complete blood count and Leishman-stained peripheral blood film examination, BM examination for French-American-British (FAB) classification [21], cytochemistry, immunophenotyping by flow cytometry, cytogenetic studies, and finally genotyping of CYP2B6 (G516T) and CYP3A4 (A290G) SNPs using polymerase chain reaction (PCR)-based restriction fragment length polymorphism (RFLP) technique.
Patients were initially treated with $3+7$ regimen, combining daunorubicin $45 \mathrm{mg} / \mathrm{m}^{2}$ IV at days $1-3$ and cytosine arabinoside (ara-C) $100 \mathrm{mg} / \mathrm{m}^{2}$ by continuous infusion from day 1 to day 7 for induction. The response was evaluated by the end of week 4. If the BM was not hypocellular and there was unequivocal residual leukemia, a second course of therapy with HAM regimen (high-dose ara-C [HiDAC] and mitoxantrone) was administered as follows: ara-C $3 \mathrm{~g} / \mathrm{m}^{2}$ from day 1 to day 3 by infusion for $3 \mathrm{~h}$ and mitoxantrone $12 \mathrm{mg} / \mathrm{m}^{2}$ from day 3 to day 5 by short infusion. After achieving complete remission (CR), consolidation chemotherapy was performed by HiDAC $\left(3 \mathrm{~g} / \mathrm{m}^{2}\right.$ for $3 \mathrm{~h}$ every $12 \mathrm{~h}$ at days 1, 3, and 5). Morphologic CR was defined according to the standard criteria by Cheson [22], namely, an absolute neutrophil count of $\geq 1.0 \times 10^{9} / \mathrm{L}$, a platelet count of $\geq 100 \times 10^{9} / \mathrm{L},<5 \%$ blasts in BM, and no extramedullary leukemia. The minimum follow-up period was 6 months. Overall survival (OS) was calculated from the date of diagnosis to death from any cause or the date of the final follow-up. Disease-free survival (DFS) was defined as the time from achieving CR to relapse or death or the date of the final follow-up.

\section{Molecular analysis \\ Sampling}

For each patient, $3-5 \mathrm{~mL}$ of venous blood was collected on ethylenediaminetetraacetic acid by sterile venipuncture using a sterile Vacutainer tube. Samples were either stored in the same Vacutainer at $-20^{\circ} \mathrm{C}$ or used directly within $24 \mathrm{~h}$ for DNA extraction.

\section{DNA extraction}

Genomic DNA was extracted from the whole blood by ready-made isolation kit (TIANamp Genomic DNA Kit catalog no. DP 318-02; TIANGEN Biotech, Beijing, China) according to the manufacturer's instructions.

\section{Genotyping}

For genotyping of the CYP2B6 (G516T) SNP, the forward primer sequence was 5'GGTCTGCCCATCTATA AAC3', and the reverse was 5'CTGATTCTTCACATGT CTGCG3'. As for the CYP3A4 (A290G) SNP, the forward primer sequence was 5`- GGA CAG CCA TAG AGA CAAGGG CC- 3 ', and the reverse primer sequence was $5^{\prime}$ - TCACTGACCTCCTTT GAG TTC ATA- 3'.

For $C Y P 2 B 6$ (G516T) SNP, the thermal cycling conditions were initial denaturation for $5 \mathrm{~min}$ at $95^{\circ} \mathrm{C}, 30 \mathrm{cy}$ cles of $30 \mathrm{~s}$ at $95^{\circ} \mathrm{C}, 30 \mathrm{~s}$ at $50^{\circ} \mathrm{C}$, and $1 \mathrm{~min}$ at $72^{\circ} \mathrm{C}$ with a final step of $10 \mathrm{~min}$ at $72^{\circ} \mathrm{C}$. For CYP3A4 (A290G) SNP, the cycling conditions were initial denaturation for $10 \mathrm{~min}$ at $95^{\circ} \mathrm{C}, 35$ cycles of $45 \mathrm{~s}$ at $95^{\circ} \mathrm{C}$, $45 \mathrm{~s}$ at $59^{\circ} \mathrm{C}$, and $1 \mathrm{~min}$ at $72^{\circ} \mathrm{C}$. The last elongation step 
was extended to $7 \mathrm{~min}$. The resulting PCR products were digested with BsrI (New England Biolabs Organic, Beverly, MA, USA) and Msp1 restriction enzyme (New England Biolabs, Ipswich, MA, USA) for the CYP2B6 (G516T) and the CYP3A4 (A290G) SNPs, respectively, according to the manufacturer's instructions. Digested fragments were separated on $2 \%$ agarose gel, and RFLP bands were visualized by ethidium bromide staining under ultraviolet light. The CYP2B6 (G516T) SNP digestion products were three fragments of 241, 268, and 17 bp when the wild-type $G$ allele was present and a single fragment of $509 \mathrm{bp}$ when the $\mathrm{T}$ mutant allele was present (Fig. 1). As for the CYP3A4 (A290G) SNP, two fragments of 142 and $23 \mathrm{bp}$ were produced when the mutant $\mathrm{G}$ allele was present and a single band of $165 \mathrm{bp}$ when the wild A allele was present (Fig. 2).

\section{Statistical methods}

Data were coded and entered using the SPSS statistics version 23 and were summarized using mean and standard deviation for quantitative variables and frequencies (number of cases) and relative frequencies (percentages) for categorical variables. Unpaired $t$-test was used to compare between quantitative variables and chi-square $\left(x^{2}\right)$ test to compare categorical data. When the expected frequency is $<5$, exact test was used instead. Genotype and allele frequencies were compared between the disease and control groups using chi-square tests. Odds ratio (OR) with $95 \%$ confidence intervals $(\mathrm{CIs})$ was calculated. $P<0.05$ was considered statistically significant.

\section{Results}

The study involved 50 newly diagnosed AML patients (AML group) and 50 age- and gender-matched healthy individuals (control group). The median age of patients was 35.9 years (range, 17-64 years); 32 (64\%) were male, and $18(36 \%)$ were female.

Upon examination of the AML group, 27 patients (54\%) had splenomegaly and 22 (44\%) had hepatomegaly. At diagnosis, the mean hemoglobin level among the studied patients was $7.9 \pm 1.9 \mathrm{~g} / \mathrm{dL}$, the platelet count ranged from 21.4 to $110.5 \times 10^{3} / \mu \mathrm{L}$ and the total leukocyte count ranged from 9.2 to $95.7 \times 10^{9} / \mathrm{L}$.

According to FAB classification, 19 patients (38\%) were classified as FAB M2, 10 (20\%) were FAB M1, 6 (12\%) were FAB M5, 6 (12\%) were FAB M4, 5 (10\%) were FAB M3, 3 (6\%) were FAB M0, and 1 (2\%) was FAB M6.

Cytogenetic analysis of the 50 AML patients revealed abnormal cytogenetics in 32 patients (64\%). The frequencies of different cytogenetic abnormalities detected in the AML group are presented in Table 1. The most frequent cytogenetic group was cytogenetically normal (normal cytogenetic [NCG]), which was detected in 18 patients followed by $t(15: 17)$. Furthermore, AML patients were stratified into three risk groups according to cytogenetic structure [23]: 14 patients (28\%) belonged to favorable-risk group, 29 (58\%) belonged to intermediate-risk group, and 7 (14\%) had poor prognosis.

The entire AML group received chemotherapy regimens. Notably, 45 patients $(90 \%)$ received $3+7$ regimen; 5 patients $(10 \%)$ received all-trans retinoic acid, whereas 3 patients (6\%) received fludarabine+HiDAC+G-CSF therapy. The initial response to therapy was assessed at day 28. CR was attained in 30 patients (60\%), whereas 6 patients died before reaching remission.

Regarding the distribution of CYP2B6 (G516T) gene polymorphism in patients and control group, the wild-

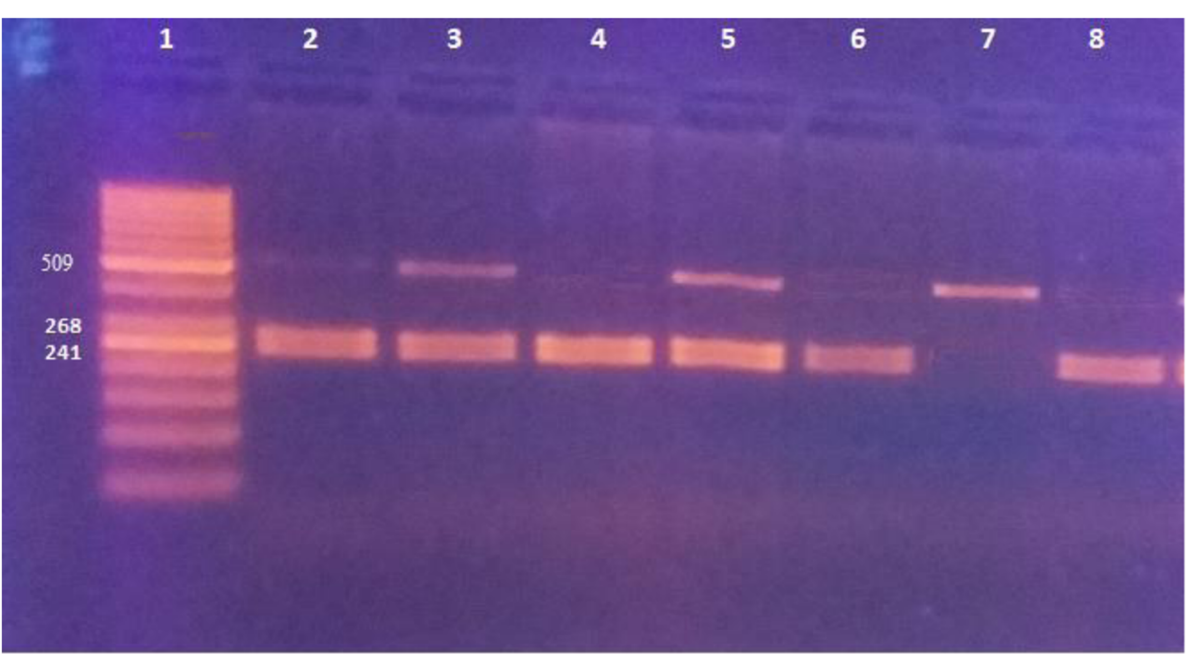

Fig. 1 PCR/RFLP detection of CYP2B6-G-516 T Polymorphism. Lane 1: 50 bp ladder. Lanes 2, 4, 6 and 8: Wild type (GG) showing two bands at 268 and $241 \mathrm{bp}$. Lanes, 3 and 5: Heterozygous mutant (GT) showing three bands at 509, 268 and 241 bps 


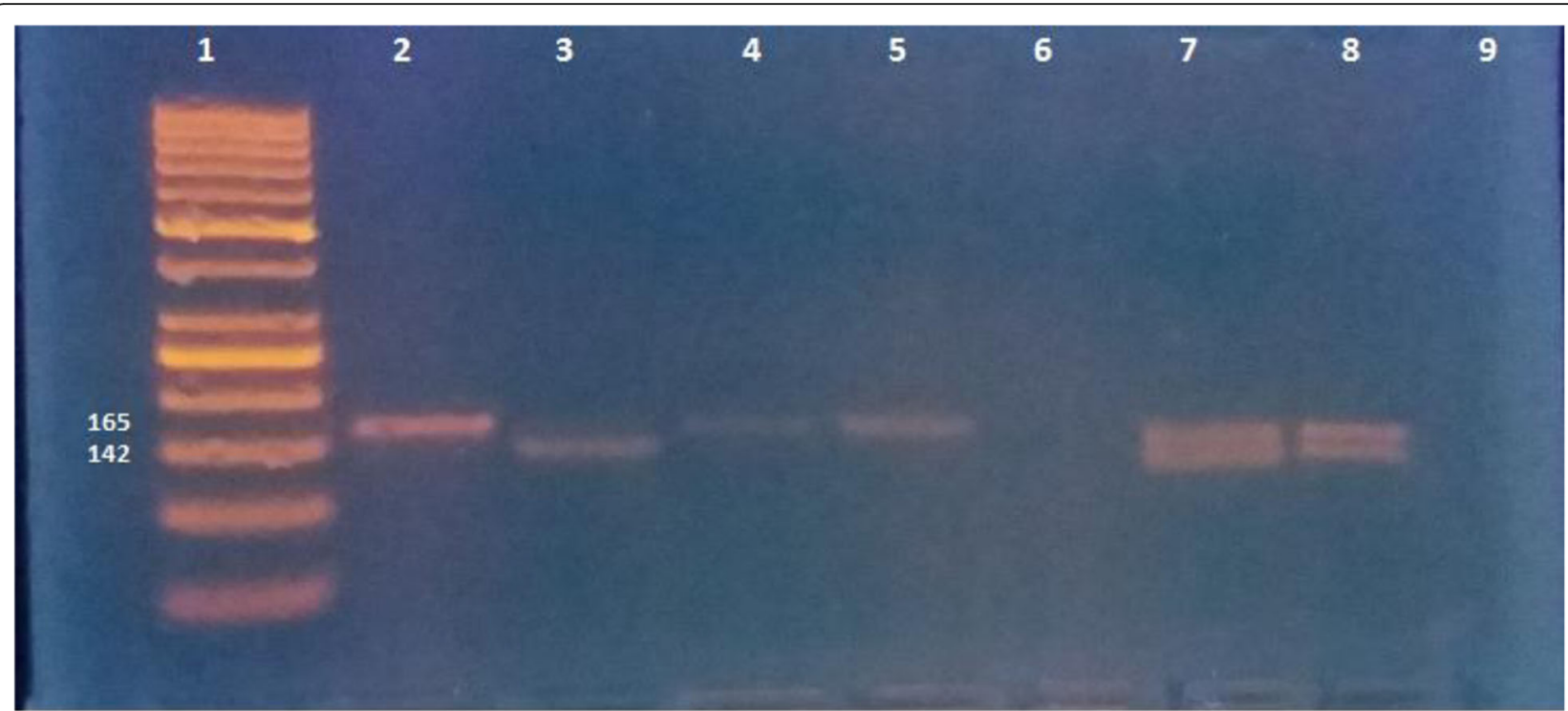

Fig. 2 PCR/RFLP detection of CYP3A4-A-290G Polymorphism. Lane 1: 50 bp ladder. Lanes 2, 4 and 5: Wild type (AA) showing one band at 165 bp. Lanes, 7 and 8: Heterozygous mutant (AG) showing two bands at 165 and 142 bps. Lane 3: Homozygous mutant (GG) showing one band at $142 \mathrm{bp}$

genotype GG was encountered in 23 AML patients (46\%) and 36 of the control group (72.0\%), the heterozygous mutant genotype GT was encountered in 19 of AML patients (38\%) and 12 of the control group (24\%), and the homozygous mutant genotype TT was encountered in 8 of AML patients (16\%) and 2 of the control group (4\%). The mutant genotype frequency distribution was significantly higher in the AML group than control subjects $(P=0.017)$ (Table 2$)$. The presence of $C Y P 2 B 6$ gene mutation (homo- or heterozygous) carries a threefold risk of developing AML (OR, 3.0; 95\% CI, 1.3-6.9) (Table 3).

CYP3A4 (A290G) gene polymorphism distribution shows that the wild genotype (AA) was encountered in 31 AML patients (62\%) and 43 of the control group (86\%), the heterozygous mutant genotype AG was encountered in 16 of AML patients (32\%) and 7 of the control group (14\%), and the homozygous mutant genotype GG was encountered in 3 of AML patients (6\%) and none of the control group. The frequency distribution of the mutant genotypes was significantly higher in

Table 1 Frequency of cytogenetic characteristics in AML group

\begin{tabular}{lll}
\hline Cytogenetic type $(\boldsymbol{n}=\mathbf{5 0})$ & Frequency $(\boldsymbol{n}=\mathbf{5 0})$ & Percent \\
\hline $\mathrm{t}(15: 17)^{\mathrm{a}}$ & 5 & 10.0 \\
$\mathrm{t}(8: 21)^{\mathrm{a}}$ & 6 & 12.0 \\
$\ln 16^{\mathrm{a}}$ & 3 & 6.0 \\
Others & 36 & 72.0 \\
\hline
\end{tabular}

${ }^{\mathrm{a}}$ Favorable prognosis cytogenetic abnormalities the patients than controls $(P=0.006)$ (Table 2). The presence of $C Y P 3 A 4$ gene mutation (homo- or heterozygous) carried an approximately fourfold risk of developing AML (OR, 3.8; 95\% CI, 1.4-10.1) (Table 3).

The distribution of the combined CYP2B6 and CYP3A4 gene mutations among patients and controls revealed only 1 case of combined gene mutation in the control group compared with 14 cases in the AML group $(P=0.003)$. The presence of combined gene mutation conferred about a 15 -fold increased risk of developing AML compared with the presence of a single gene mutation (OR, 14.8; 95\% CI, 1.8-124.2) (Table 3).

The gene polymorphism of both CYP2B6 and CYP3A4 did not show any association with demographic, clinical,

Table 2 CYP2B6 gene polymorphism distribution in the two studied groups

\begin{tabular}{cclc}
\hline Genotype & $\begin{array}{l}\text { AML group } \\
\boldsymbol{n}=\mathbf{5 0}\end{array}$ & $\begin{array}{l}\text { Control group } \\
\boldsymbol{n}=\mathbf{5 0}\end{array}$ & $\boldsymbol{p}$ value \\
\hline \multicolumn{2}{c}{ CYP2B6 gene polymorphism } & & \\
GG & $23(46 \%)$ & $36(72 \%)$ & 0.017 \\
GT & $19(38 \%)$ & $12(24 \%)$ & \\
$\pi$ & $8(16 \%)$ & $2(4 \%)$ & 0.008 \\
GT + TT & $27(54 \%)$ & $14(28 \%)$ & \\
CYP3A4 gene polymorphism & & $\mathbf{0 . 0 0 6}$ \\
AA & $31(62.0 \%)$ & $43(86 \%)$ & \\
AG & $16(32.0 \%)$ & $7(14 \%)$ & $\mathbf{0 . 0 0 6}$ \\
GG & $3(6.0 \%)$ & $0(0 \%)$ & $7(14 \%)$ \\
AG + GG & $19(38 \%)$ & &
\end{tabular}


Table 3 Risk estimate for AML in the two studied genes

\begin{tabular}{|c|c|c|c|c|c|}
\hline & AML & Control & OR & $95 \% \mathrm{Cl}$ & $p$-value \\
\hline \multicolumn{6}{|c|}{ CYP2B6 gene polymorphism } \\
\hline GG & $23(46 \%)$ & $36(72 \%)$ & 3.0 & $1.3-6.9$ & 0.008 \\
\hline $\mathrm{GT}+\pi$ & 27 (54\%) & $14(28 \%)$ & & & \\
\hline
\end{tabular}

CYP3A4 gene polymorphism

$\begin{array}{llllll}\text { AA } & 31(62 \%) & 43(86 \%) & 3.8 & 1.4-10.1 & \mathbf{0 . 0 0 6} \\ \mathrm{AG}+\mathrm{GG} & 19(38 \%) & 7(14 \%) & & & \end{array}$

CYP2B6 gene polymorphism + CYP3A4 gene polymorphism

\begin{tabular}{llllll} 
Combined & $14(43.7 \%)$ & $1(5.0 \%)$ & 14.8 & $1.8-124.2$ & $\mathbf{0 . 0 0 3}$ \\
Single & $18(56.3 \%)$ & $19(95.0 \%)$ & & & \\
\hline
\end{tabular}

$O R$ odds ratio, $\mathrm{Cl}$ confidence interval

or laboratory characteristics of the AML patients (Table 4).

Cytogenetic risk stratification showed a significant association between CYP3A4 gene mutation and unfavorable cytogenetic risk $(P=0.031)$. The presence of CYP3A4 mutation was found to be a risk factor for unfavorable cytogenetic profile in AML patients (OR, 2.8; 95\% CI, 0.8-10.2). However, there was no significant association between $C Y P 2 B 6$ gene mutation and cytogenetic risk stratification (Table 5).

\section{Overall survival}

The cumulative OS proportion of AML patients was $48.5 \%$ at 9 months. The median survival time was 9 months (95\% CI, 7.8-10.2 months). CYP3A4 mutation was associated with worse OS $(P=0.030)$ (Fig. 3). In contrast, OS was not affected by the presence of $C Y P 2 B 6$ gene mutations $(P=0.827)$ (Table 6).

Those with combined $C Y P 2 B 6$ and $C Y P 3 A 4$ gene mutations had worse OS than AML patients with a single gene mutation: the median survival time was 12.0 months (95\% CI, 8.7-15.3) in cases with wild CYP3A4 genotype, whereas 9.0 months (95\% CI, 7.8-10.2) in the mutant genotype $(P=0.030)$ (Fig. 4$)$.

\section{Disease-free survival}

At 9 months, the cumulative DFS proportion of the 30 AML patients who achieved CR was $44.6 \%$. The median DFS was 9 months (95\% CI, 5.8-12.2 months). DFS was not affected by the presence of $C Y P 2 B 6$ gene mutations $(P=0.352)$ or $C Y P 3 A 4$ mutation $(P=0.195)$. In addition, no significant difference was found in DFS among patients with a single gene mutation of one of the CYP2B6 and CYP3A4 genes compared with those with combined mutations $(P=0.265)$ (Table 7$)$.

\section{Discussion}

AML is a form of cancer characterized by the infiltration of malignant cells to the blood, BM, and other tissues. Fifty years ago, AML was incurable; however, a few years ago, the prognosis improved and now AML is curable in $35 \%-40 \%$ of adult patients aged $\leq 60$ years [23].

The exact causes of leukemia are still unknown despite widespread studies that investigated the mechanisms of the disease. It is believed that the exposure of DNA to reactive oxygen species in the hematopoietic stem cells is an important factor in the development of leukemia [24]. CYP enzymes play an important role in the elimination of oxidative stress.

Genetic polymorphisms in these enzyme systems are associated with the reduction of CYP enzymes; thus, it can influence cancer susceptibility $[8,9]$.

The current work studied the possible association between CYP2B6 (G516T) and CYP3A4 (A290G) gene polymorphisms and susceptibility to AML in the Egyptian population and the association between CYP genotypes and the clinical presentation, hematological and cytogenetic findings, and treatment response in AML

Table 4 Relation of CYP2B6 gene polymorphism and CYP3A4 gene polymorphism with demographic, clinical and laboratory data in AML patients

\begin{tabular}{|c|c|c|c|c|c|c|}
\hline & \multicolumn{3}{|c|}{ CYP2B6 gene polymorphism } & \multicolumn{3}{|c|}{ CYP3A4 gene polymorphism } \\
\hline & Wild & Hetero + Homo & $p$ value & Wild & Hetero + Homo & $p$ value \\
\hline Median Age (years) & 32.4 & 37.6 & 0.379 & 35.4 & 40.1 & 0.418 \\
\hline \multicolumn{7}{|l|}{ Sex, No (\%) } \\
\hline Male & $14(48.2 \%)$ & $15(51.8 \%)$ & 0.704 & $19(65.5 \%)$ & $10(34.5 \%)$ & 0.547 \\
\hline Female & $9(42.8 \%)$ & $12(57.2 \%)$ & & $12(57.1 \%)$ & $9(42.9 \%)$ & \\
\hline Splenomegaly, No. (\%) & $15(55.5 \%)$ & $12(44.5 \%)$ & 0.141 & $17(63.0 \%)$ & $10(37.0 \%)$ & 0.879 \\
\hline Hepatomegaly, No. (\%) & $12(54.5 \%)$ & $10(45.5 \%)$ & 0.282 & $14(63.6 \%)$ & $8(36.4 \%)$ & 0.833 \\
\hline Hemoglobin (g/dL) & $7.5 \pm 1.4$ & $7.9 \pm 2.0$ & 0.476 & $7.8 \pm 1.9$ & $8.1 \pm 1.9$ & 0.535 \\
\hline Median TLC $\left(\times 10^{3} / \mathrm{mm}^{3}\right)$ & 42.8 & 56.4 & 0.722 & 60.3 & 53.4 & 0.542 \\
\hline Median Platelet count $\left(\times 10^{3} / \mathrm{mm}^{3}\right)$ & 68.4 & 50.8 & 0.784 & 78.6 & 66.4 & 0.810 \\
\hline
\end{tabular}


Table 5 Relation between cytogenetic risk stratification and CYP gene mutations

\begin{tabular}{|c|c|c|c|c|}
\hline & Favorable (cytogenetic) $(n=14)$ & Intermediate + poor (cytogenetic) $(n=36)$ & $P$ value & OR $(95 \% \mathrm{Cl})$ \\
\hline \multicolumn{5}{|l|}{ CYP2B6 } \\
\hline Wild (GG) & $9(64.3 \%)$ & $14(18.5 \%)$ & 0.106 & $2.8(0.8-10.2)$ \\
\hline Mutant $(\mathrm{GT}+\mathrm{TT})$ & $5(35.7 \%)$ & $22(81.5 \%)$ & & \\
\hline \multicolumn{5}{|l|}{ CYP3A4 } \\
\hline Wild (AA) & $12(85.7 \%)$ & $19(52.8 \%)$ & 0.031 & $5.4(1.0-27.5)$ \\
\hline Mutant (AG + GG) & $2(14.3 \%)$ & $17(47.2 \%)$ & & \\
\hline
\end{tabular}

$O R$ odds ratio, $\mathrm{Cl}$ confidence interval

cases to justify whether such polymorphisms have any effect on the disease prognosis.

In this study, the mutant $C Y P 2 B 6$ genotypes were significantly higher in patients than controls $(P=0.017)$. Calculated risk estimation revealed that the mutant genotypes conferred a threefold increased risk of developing AML (OR, 3.3; 95\% CI, 1.3-6.9).

In 2009, Bekroz et al. investigated the association between $C Y P 2 B 6$ gene polymorphism and the susceptibility to acute leukemia in the Turkish population. Their study included 80 acute leukemia patients (44 of the

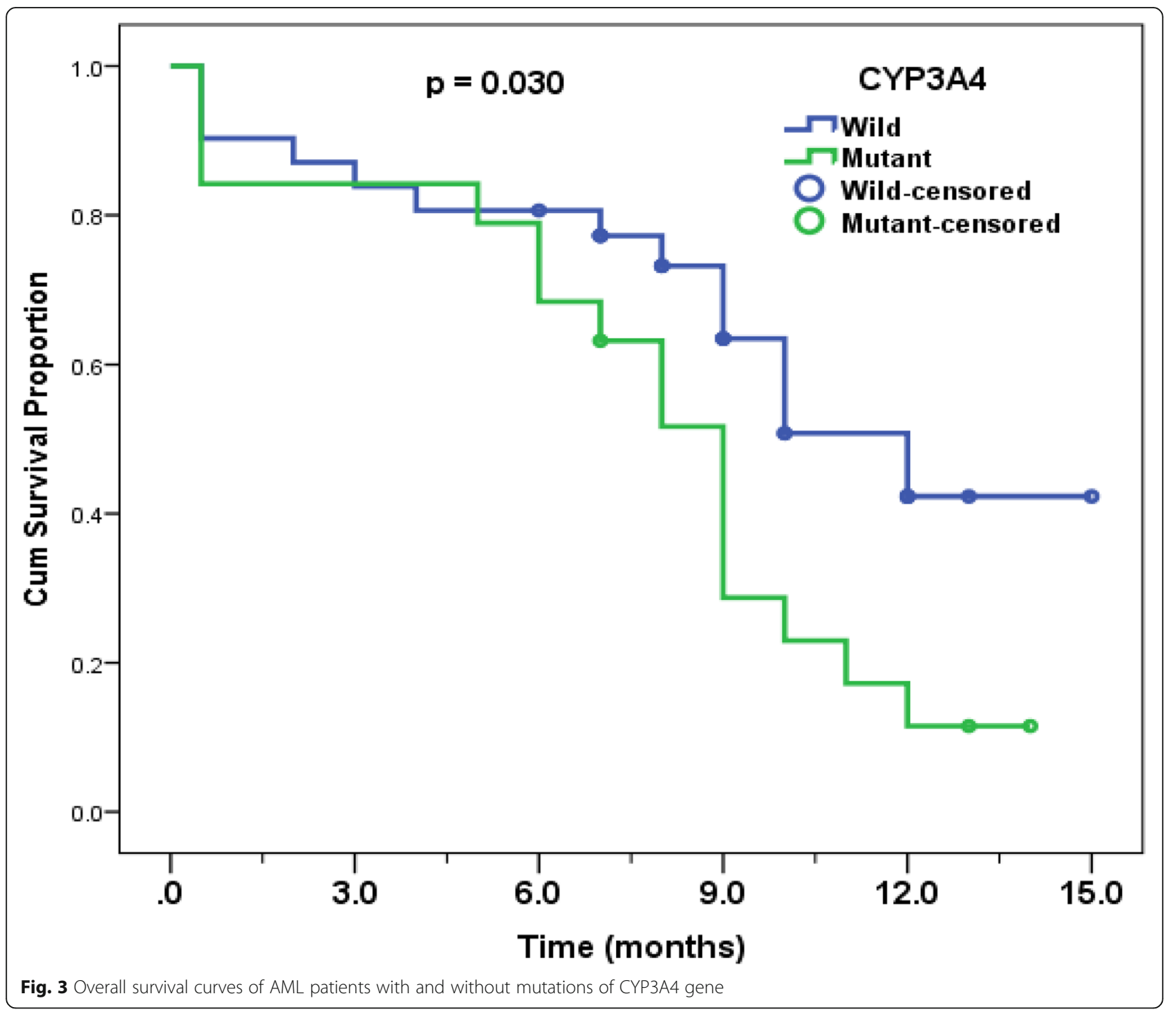


Table 6 Overall survival of AML patients in relation to gene polymorphism of CYP2B6 and CYP3A4

\begin{tabular}{|c|c|c|c|c|}
\hline & $N$ & 9 months Cumulative Survival (\%) & Median Survival time $(95 \% \mathrm{Cl})$ (months) & $p$ value \\
\hline Whole group & 50 & 48.5 & $9.0(7.8-10.2)$ & \\
\hline \multicolumn{5}{|l|}{ CYP2B6 } \\
\hline Wild & 23 & 64.3 & $10.0(7.8-12.2)$ & \\
\hline Mutant & 27 & 34.9 & $9.0(8.3-9.7)$ & 0.827 \\
\hline \multicolumn{5}{|l|}{ CYP3A4 } \\
\hline Wild & 31 & 63.5 & $12.0(8.7-15.3)$ & 0.030 \\
\hline Mutant & 19 & 28.7 & $9.0(7.8-10.2)$ & \\
\hline \multicolumn{5}{|l|}{ Single vs. Combined } \\
\hline Single Mutation & 18 & 62.2 & $11.0(8.1-13.9)$ & 0.030 \\
\hline Combined Mutations & 14 & 16.1 & $8.0(6.3-9.7)$ & \\
\hline
\end{tabular}

patients had acute lymphocytic leukemia [ALL] and 36 had AML) and 100 control subjects [25]. Logistic regression analyses revealed a significant correlation between the CYP2B6 (G516T) polymorphism and patients with acute leukemia (OR, 2.481; 95\% CI, 1.353-4.551; $P=$ $0.003)$. In addition, in agreement with our results, Yuan et al. (2011) reported that the GT and GT + TT genotype frequencies of c.516G $>\mathrm{T}$ SNP were higher in ALL (37.5\% and 42.7\%, respectively; $P<0.01$ ) and AML (37.2\% and $40.9 \%$, respectively; $P<0.01$ ) than control subjects [13].
Regarding the CYP3A4 (A290G) SNP, the mutant genotypes were overrepresented in patients compared with the control subject $(P=0.006)$. The presence of the mutation, whether homozygous or heterozygous, carried an approximately fourfold increased risk of developing AML (OR, 3.8; 95\% CI, 1.4-10.1).

In agreement with our data, Ali et al., in a case-control study involving 77 newly diagnosed AML cases and 72 age- and sex-matched healthy controls, reported a high frequency of the homozygous genotype (GG) in AML cases, although not statistically significant $(P=0.999)$.

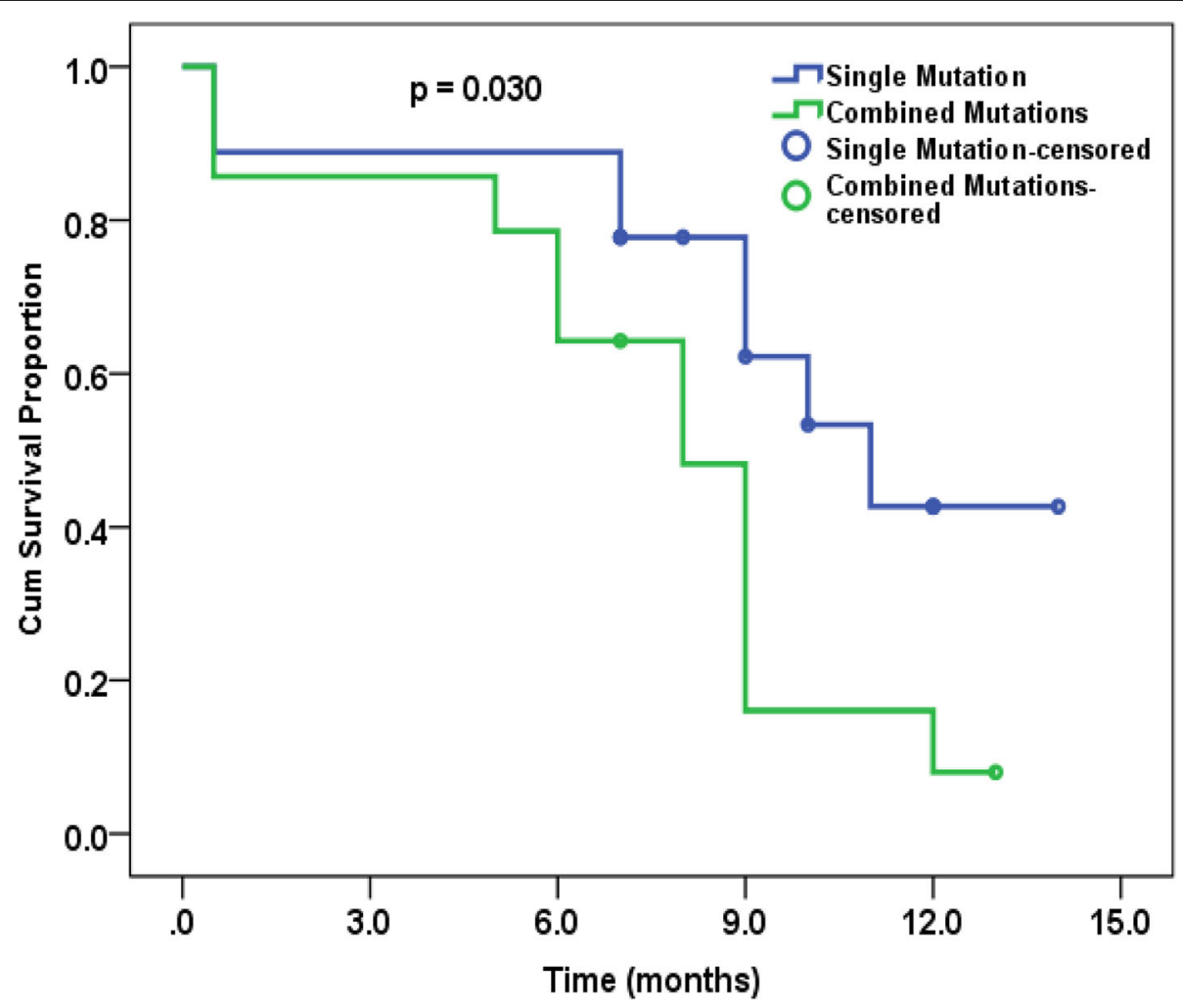

Fig. 4 Overall survival curves of AML patients with single and combined mutations of CYP2B6 and CYP3A4 genes 
Table 7 Disease-free survival of AML patients in relation to gene polymorphism of CYP2B6 and CYP3A4

\begin{tabular}{|c|c|c|c|c|}
\hline & $n$ & 9 months Cumulative Survival (\%) & Median Survival time $(95 \% \mathrm{Cl})$ (months) & $p$ value \\
\hline Whole group & 30 & 46.6 & $9.0(5.8-12.2)$ & \\
\hline \multicolumn{5}{|l|}{ CYP2B6 } \\
\hline Wild & 12 & 63.5 & * & \\
\hline Mutant & 18 & 38.5 & $8.0(6.0-10.0)$ & 0.352 \\
\hline \multicolumn{5}{|l|}{ CYP3A4 } \\
\hline Wild & 20 & 50.7 & * & 0.195 \\
\hline Mutant & 10 & 36.0 & $7.0(4.3-9.7)$ & \\
\hline \multicolumn{5}{|l|}{ Single vs. Combined } \\
\hline Single Mutation & 12 & 46.9 & * & 0.265 \\
\hline Combined Mutations & 8 & 31.3 & $7.0(4.7-9.3)$ & \\
\hline
\end{tabular}

*No median survival time because more than half of the patients were alive free of disease

The $\mathrm{G}$ allele was significantly frequent in AML cases $(P=0.001$; OR, 17.9; 95\% CI, 4.041-78.903) [26].

Similar to our results, Voso et al., in a case-control study involving 160 cases of AML and 162 matched controls, reported a significantly higher prevalence of the polymorphic variant CYP3A4 (A290G) genes in AML cases than controls $(9.4 \%$ vs $3.1 \% ; P=0.04)$, increasing the risk of developing AML to 3.2-fold (95\% CI, 1.111.5) [14].

In contrast, Pakakasama et al. analyzed 107 children with ALL and 320 healthy controls for CYP3A4 (A290G) polymorphism and reported an insignificant difference in the distribution of the polymorphism between patients and controls [25]. This difference may be explained by the variability of the risk factor for acute leukemia between children and adults.

Naoe et al. studied the CYP3A4 (A290G) polymorphism in 58 patients with $\mathrm{t}$-AML/t-MDS and 150 Japanese healthy individuals and found that all subjects had the wild genotype, except 1 case that had a heterogeneous genotype, indicating a very low frequency or a lack of CYP3A4 (A290G) polymorphism in the Japanese population [27]. This may be explained by ethnic variability.

The distribution of combined CYP2B6 and CYP3A4 gene mutations was also significantly increased in patients compared with controls $(P=0.003)$. The presence of combined gene mutation carried an approximately 15-fold increased risk of developing AML compared with the presence of a single gene mutation. To the best of our knowledge, no published study investigated the risk of this combined gene polymorphism and AML.

Similar to these results are those reported by Alazhary $\mathrm{NM}$ et al. (2015), who found no significant association between CYP2B6 polymorphism and $C R$, cytogenetic analysis, and OS [28]. A cytogenetic analysis of $50 \mathrm{AML}$ patients revealed abnormal cytogenetics in 32 patients (64\%) and NCG in 18 patients (36\%). Risk stratification according to the cytogenetic makeup of AML patients revealed 14 favorable $(28 \%)$ and 36 nonfavorable patients (72\%). In this study, no significant association was found between the presence of mutation in the CYP2B6 gene and cytogenetic risk stratification of AML patients. In contrast, a significant association was found between CYP3A4 gene mutation and unfavorable cytogenetic risk.

In another study, Sophia et al. (2014) reported a higher frequency of the mutant CYP2B6 (G516T) allele in patients with poor prognosis based on cytogenetic findings, indicating that the presence of the variant allele is probably related to specific chromosomal abnormalities conferring a poor prognosis [29].

Furthermore, we found that CYP3A4 (A290G) mutation was significantly associated with worse OS $(P=$ $0.030)$. In contrast, $O S$ was not affected by the presence of $C Y P 2 B 6$ gene mutations $(P=0.827)$. Patients carrying mutation of both genes had worse OS $(P=0.030)$ than patients with a single gene mutation.

DFS was not affected by the presence of $C Y P 2 B 6$ gene mutations $(P=0.352)$ or CYP3A4 gene mutation $(P=$ $0.195)$. In addition, there was no significant difference in DFS between patients with a single gene mutation of one of the CYP2B6 and CYP3A4 genes compared with those with combined mutations $(P=0.265)$.

Similarly, Ali et al. (2013) reported that there was no significant association between CYP3A4 (A290G) SNP and different clinical or laboratory parameters and the early response to treatment, OS, and the DFS [26].

\section{Conclusion}

The results of this study provide an evidence for the possible pathogenetic role of the CYP2B6 and CYP3A4 polymorphisms on the risk of developing AML. Moreover, having combined mutation in both genes increases such risk. CYP3A4 polymorphism was associated with an unfavorable cytogenetic risk and worse OS, suggesting that CYP3A4 may have a role in disease progression, 
therapeutic outcome, DFS, and OS in AML patients, whereas $C Y P 2 B 6$ mutations were not associated with such findings. Oxidative stress is an important risk factor for the development of AML. The elimination of oxidative stress in genetically susceptible individuals may decrease the risk of AML and may improve survival.

Further studies are needed to be conducted on a larger sample size and on other populations to verify the prognostic implications of the CYP2B6 and CYP3A4 polymorphisms on treatment outcome and disease progression.

\section{Abbreviations}

Cyp: Cytochrome p 450; RFLP: Restriction fragment length polymorphism; SNP: Single nucleotide polymorphism; PCR: Polymerase chain reaction; FAB: French-American-British; DFS: Disease free survival

\section{Acknowledgements}

Special thanks are dedicated to clinical pathology department, Faculty of medicine, Cairo university professors, workers and for our Egyptian patients without whom this work would have not been completed.

\section{Authors' contributions}

NG: Study design. SB: Revision of the manuscript. GS: interpretation of data. HL: Data analysis. MS: Study design, drafting the work. All authors have read and approved the manuscript. All authors agreed both to be personally accountable for the author's own contributions and to ensure that questions related to the accuracy or integrity of any part of the work, even ones in which the author was not personally involved, are appropriately investigated, resolved, and the resolution documented in the literature.

\section{Funding}

This study was funded by the authors only.

\section{Availability of data and materials}

Availability of data and materials: they are available from Nasser research institute for research and treatment but restrictions apply to the availability of these data and so are not publicly available. Data are however available from the corresponding author upon reasonable request.

\section{Declarations}

\section{Ethics approval and consent to participate}

The study was approved by the Research Ethics Committee (REC) of Cairo University Hospitals. (reference number, I-251014) A written informed consent was obtained from each participant.

\section{Consent for publication}

Not applicable.

\section{Competing interests}

The authors have no conflicts of interest to disclose.

\section{Author details}

${ }^{1}$ Clinical Pathology, Kasr Al Ainy Medical School, 26 Atbara st., Agouza, Giza 12411, Egypt. ${ }^{2}$ Internal Medicine, Kasr Al Ainy medical School, Giza, Egypt. ${ }^{3}$ Nasser Institute for Research and Treatment, Cairo, Egypt.

Received: 10 April 2020 Accepted: 9 February 2021

Published online: 06 April 2021

\section{References}

1. Deschler B, Lubbert M et al (2006) Acute myeloid leukemia: epidemiology and etiology. Cancer 107:2099-2107.

2. Lowenberg B, Downing JR, Burnett A (1999) Acute myeloid leukemia. N Engl J Med 341:1051-1062

3. Estey E, Dohner H (2006) Acute myeloid leukemia. Lancet. 368:1894-1907
4. Roy P, Yu L, Crespi CL, Waxman DJ (1999) Development of a substrateactivity based approach to identify the major human liver P-450 catalysts of cyclophosphamide and ifosfamide activation based on CDNA-expressed activities and liver microsomal P-450 profiles. Drug Metab Dispos. 27:655-666.

5. Antona RC, Ingelman-Sundberg M (2006) Cytochrome P450 pharmacogenetics and cancer. Oncogene 25:1679-1691.

6. Zanger UM, Turpeinen M, Klein K, Schwab M (2008) Functional pharmacogenetics/genomics of human cytochromes P450 involved in drug biotransformation. Anal Bioanal Chem 392(6):1093-1108.

7. Hoffman SM, Fernandez-Salguero P, Gonzalez FJ et al (1995) Organization and evolution of the cytochrome P450 CYP2A-2B-2F subfamily gene cluster on human chromosome 19. J Mol Evol 41:894-900.

8. Dong LM, Potter JD, White E et al (2008) Genetic susceptibility to cancer: the role of polymorphisms in candidate genes. JAMA. 299:2423-2436.

9. Agundez JA (2004) Cytochrome P450 gene polymorphism and cancer. Curr Drug Metab 5:211-224.

10. Bozina N, Bradamante V, Lovrić M (2009) Genetic polymorphism of metabolic enzymes P450 (CYP) as a susceptibility factor for drug response, toxicity, and cancer risk. Arh Hig Rada Toksikol 60:217-242.

11. Majumdar S, Mondal BC, Ghosh M, Dey S, Mukhopadhyay A et al (2008) Association of cytochrome P450, glutathioneS-transferase and $\mathrm{N}$ acetyltransferase 2 gene polymorphisms with incidence of acute myeloid leukemia. Eur J Cancer Prev 17:125-132.

12. Berköz M, Yalin S (2009) Association of CYP2B6 G15631T polymorphism with acute leukemia susceptibility. Leuk Res 33:919-923.

13. Yuan ZH, Liu Q, Zhang Y et al (2011) CYP2B6 gene single nucleotide polymorphisms and leukemia susceptibility. Ann Hematol 90:293-299.

14. Voso MT, Fabiani E, D'Alo' F et al (2007) Increased risk of acute myeloid leukaemia due to polymorphisms in detoxification and DNA repair enzymes. Ann Oncol 18:1523-1528.

15. Hofmann MH, Blievernicht JK, Klein K et al (2008) Aberrant splicing caused by single nucleotide polymorphism c.516G.T [Q172H], a marker of CYP2B6*6, is responsible for decreased expression and activity of CYP2B6 in liver. J Pharmacol Exp Ther 325:284-292.

16. Felix CA, Walker AH, Lange BJ et al (1998) Association of CYP3A4 genotype with treatment-related leukemia. Proc Natl Acad Sci U S A 95(22):13176-13181.

17. Rebbeck TR, Jaffe JM, Walker AH et al (1998) Modification of clinical presentation of prostate tumors by a novel genetic variant in CYP3A4. J Nat Cancer Inst 90(16):1225-1229 Erratum in: J Natl Cancer Inst 1999 Jun 16;91 (12):1082. PMID: 9719084.

18. Ball SE, Scatina J, Kao J, Ferron GM, Fruncillo R, Mayer P, Weinryb I, Guida M, Hopkins PJ, Warner N, Hall J (1999) Population distribution and effects on drug metabolism of a genetic variant in the $5^{\prime}$ promoter region of CYP3A4. Clin Pharmacol Ther 66(3):288-294.

19. Paris PL, Kupelian PA, Hall JM et al (1999) Association between a CYP3A4 genetic variant and clinical presentation in African-American prostate cancer patients. Cancer Epidemiol Biomark Prev 8(10):901-905.

20. Wandt $\mathrm{H}$, Haferlach $\mathrm{T}$, Thiede $\mathrm{C}$ et al (2010) WHO classification of myeloid neoplasms and leukemia. Blood 115(3):748-749; author reply 749-50. https://doi.org/10.1182/blood-2009-10-249664.

21. Neame PB, Soamboonsrup P, Browman GP et al (1986) Classifying acute leukemia by immunophenotyping: a combined $F A B$ immunologic classification of AML. Blood. 68(6):1355-1362.

22. Cheson BD, Bennett JM, Kopecky KJ, International Working Group for Diagnosis, Standardization of Response Criteria, Treatment Outcomes, and Reporting Standards for Therapeutic Trials in Acute Myeloid Leukemia et al (2003) Revised recommendations of the international working Group for Diagnosis, standardization of response criteria, treatment outcomes, and reporting standards for therapeutic trials in acute myeloid leukemia. J Clin Oncol 21(24):4642-4649.

23. Döhner H, Weisdorf DJ, Bloomfield CD (2015) Acute Myeloid Leukemia. N Engl J Med 373(12):1136-1152. https://doi.org/10.1056/NEJMra1406184.

24. Mandegary A, Rostami S, Alimoghaddam K et al (2011) Gluthatione-Stransferase T1-null genotype predisposes adults to acute promyelocytic leukemia; a case-control study. Asian Pac J Cancer Prev 12(5):1279-1282.

25. Pakakasama S, Mukda E, Sasanakul W et al (2005) Polymorphisms of drug-metabolizing enzymes and risk of childhood acute lymphoblastic leukemia. Am J Hematol 79:202-205.

26. Ali GT, Al-azhary NM, Mokhtar DA (2014) Frequency and prognostic significant of CYP3A4-a-290G polymorphism in acute myeloid leukemia. J Adv Res 5(6):657-661 
27. Naoe T (2000) Analysis of genetic polymorphism in NQO1, GST-M1, GST-T1, and CYP3A4 in 469 Japanese patients with therapy-related leukemia/ Myelodysplastic syndrome and de novo acute myeloid leukemia. Clin Cancer Res 6:4091-4095

28. Alazhary NM, Shafik RE, Shafik HE et al (2015) Prognostic value of a CYP2B6 gene polymorphism in patients with acute myeloid leukemia. Asian Pac J Cancer Prev 16(11):4583

29. Daraki A, Zachaki S, Koromila T et al (2014) The G ${ }^{516}$ T CYP2B6 Germline polymorphism affects the risk of acute myeloid leukemia and is associated with specific chromosomal abnormalities. PLoS One 9(2):e88879. https://doi. org/10.1371/journal.pone.0088879 Cai T, ed

\section{Publisher's Note}

Springer Nature remains neutral with regard to jurisdictional claims in published maps and institutional affiliations.

\section{Submit your manuscript to a SpringerOpen ${ }^{\circ}$ journal and benefit from:}

- Convenient online submission

- Rigorous peer review

- Open access: articles freely available online

- High visibility within the field

- Retaining the copyright to your article

Submit your next manuscript at $\boldsymbol{\nabla}$ springeropen.com 